\title{
Taboo Semantics
}

\author{
Carl Vogel \\ Centre for Computing and Language Studies, Computational Linguistics Group \\ School of Computer Science and Statistics \\ Trinity College Dublin, Dublin 2, Ireland \\ email: vogeletcd.ie
}

\begin{abstract}
Phenomena related to linguistic taboos are discussed and analyzed within a framework for truth-conditional semantics for natural language.

Index Terms-offensive content, taboo, impoliteness, politeness, excessive politeness, semantics, pragmatics

\section{INTRODUCTION}

Taboo emerges from the extremities of human value systems. Freud [1, p. 33] quotes Northcote W. Thomas: ${ }^{1}$

Properly speaking taboo includes only (a) sacred (or unclean) character of persons or things, (b) the kind of prohibition which arises from this character, and (c) the sanctity (or uncleanliness) which results from a violation of the prohibition.
\end{abstract}

Popular current usage evidently does not include (c). However, anthropological study of taboo attends to the communicability of associated uncleanliness. This article addresses (a) and (c) in relation to violations of (b) through communicative action and linguistic expression.

Some expressions in natural language have come to be regarded as taboo, and although it is not the case that there is a universal semantic basis that can be used to reliably predict taboo expressions [2], and despite the fact that the inventory of expressions that are prohibited through taboo varies with time within any one language (e.g., [3]), it is nonetheless claimed that every culture has taboo [4]. ${ }^{2}$ Taboo expressions may have superlatively negative or positive connotations. However, the positives, associated with sacred expressions, also involve the dread of accompanying negatives. Polite and impolite conversation make differing responses to taboo expressions: polite conversation avoids taboo, but impolite conversation is not defined as that which includes taboo expressions-impolite conversation may perceived as impolite without reaching the extreme of including taboo.

Aspects of taboo language have been discussed among a number of other puzzles of the language of politeness and impoliteness [8]. This paper provides primary focus on taboo expressions, elaborating some of their anomalous qualities.

\footnotetext{
${ }^{1}$ From the eleventh edition of the Encyclopedia Britannica.

${ }^{2}$ The relationship between behavioral taboo and linguistic taboo is interesting. Claims appear to be most robust for a universal behavioral taboo prohibiting incest, notwithstanding that this does not prevent incest. I do not know of evidence of a semantic prime that underlies a universal linguistic taboo. Evidently, the closest is the notion of "feeling bad" [5], [6]. Further, some pervasive loci of taboo have been identified, even if the cross-cultural reactions to these loci differ: e.g., naming, bodily excretions, foods, death [7].
}

A formal semantic analysis of these expressions is provided, again using a semantic framework recently developed for the analysis of (im)politeness [9]. Within this framework, taboo is an extreme of impoliteness.

The semantic theory applied here is informed by the view that politeness and impoliteness behaviors are manifestations of efforts to manage the generalized effects of the human disgust response [9]. Ultimately, the idea here is that it is the desire not to be ostracized as disgusting which prompts politeness and the perception of disgust which elicits impoliteness. The human disgust response is extremely powerful [10][12]: disgust triggers are generally experienced as irreversibly polluting; the disgust response generalizes from primary triggers to associates in unimpeded contagions; associates may be conceptual or tangible; the response includes subsequent avoidance of the trigger category following even a single exposure. ${ }^{3}$ As the disgust response is so powerful, potentially leading to ostracism, social agents have a particular interest in being able to manage the offence that arises from disgust, and it has been suggested that (im)politeness behaviors evolved exactly for this purpose [14].

Theories of (im)politeness have tended to be couched within pragmatic theory. ${ }^{4}$ Invoking Goffman's analysis of human interactions in terms of "face" [16], [17], much research has studied politeness as "facework" [18]. In contrast, others [19]-[21] give priority to the "relational work" taken on by communicating agents. In caricature, in the terms of networks, "facework" approaches may be seen as attending mainly to the nodes (the agents), while the "relational work" approaches may be thought of as focused mainly on the links (relations between agents). The disgust-management analysis addresses the same networks, but construes (im)politeness as the toolset used to manage the "fog of offence" that might otherwise permeate the networks.

The paper proceeds by describing some of the interesting properties of taboo language ( $\S$ II). In $\S$ III a semantic theory

\footnotetext{
${ }^{3}$ The methodological difficulty associated with declaring any particular human emotion a cultural universal is duly noted: it may be accepted that disgust is not lexicalized universally nor the language-specific labels used in all its senses, including metaphorically, the way it is in English [13], and disgust triggers may be acknowledged as culture-specific as well; nonetheless, the physical disgust response - oral-nasal nausea-sympathetic expulsion reflex evidently is universal along with its capacity to generalize [12], regardless of how parochial its triggers may be.

${ }^{4}$ Of course, prominent pragmatic theorists acknowledge that (im)politeness expressions are amenable to analysis within linguistic theory [15].
} 
of (im)politeness is detailed, and $\S \mathrm{IV}$ analyzes taboo language within this framework. Essentially, the theory holds that flaunting linguistic taboo evokes maximal disgust and therefore exemplifies maximal impoliteness.

\section{TABOO LANGUAGE}

\section{A. Some linguistic forms}

It is common in formal semantics to define a meaning function "[.]" that relates natural language expressions to their meanings. Normally, this is thought of as a one to potentially many function of linguistic expressions. Briefly consider the inverse of this function, " $\llbracket . \rrbracket^{-1}$ ", as it relates to the following definitions from the Oxford English Dictionary.

(1) $w^{1}=\{w \mid$ [the usual form, among scholars, of the personal name of God in the Old Testament, representing the most likely vocalization of the sacred tetragrammaton $\rrbracket^{-1}$ $=w\}$

(2) $w^{2}=\left\{w \mid \llbracket\right.$ an act of sexual intercourse $\left.\rrbracket^{-1}=w\right\}$

(3) $w^{3}=\left\{w \mid \llbracket\right.$ the female genitals $\left.\rrbracket^{-1}=w\right\}$

(4) $w^{4}=\left\{w \mid \llbracket\right.$ the glans penis $\left.\rrbracket^{-1}=w\right\}$

(5) $w^{5}=\left\{w \mid \llbracket\right.$ excrement from the bowels $\left.\rrbracket^{-1}=w\right\}$

Notice that, perhaps except for $w^{1}$, each of the $w^{i}$ has more than one possible lexicalization in English - among them are euphemisms, orthophemisms and dysphemisms (the latter contain the taboo expressions). ${ }^{5}$ The literal lexical meanings themselves are not taboo. For convenience, define a function $T$ as in (6) that picks out the taboo form in a set of expressions if it exists. ${ }^{6}$

(6) $T(w)=x \in w, x$ is taboo.

(7) $\Omega(w)=x \in w, x$ is an orthophemism.

(8) $E(w)=x \in w, x$ is an euphemism.

A contrast between taboo and orthophemism is that the full meaning of a taboo expression is not exhausted by its literal lexical semantics, as indicated by (9) and (10).

(9) $\llbracket \Omega\left(w^{2}\right) \rrbracket=\llbracket$ an act of sexual intercourse $\rrbracket$

(10) $\llbracket T\left(w^{2}\right) \rrbracket \neq \llbracket$ an act of sexual intercourse $\rrbracket$

In fact, relatively few expressions in English with $T\left(w^{2}\right)$ as a constituent have anything really to do with sexual intercourse. Rather, they are utterances that express "a level of contempt unparalleled by nontaboo words" [2, p. 155].

\section{B. Observations on the data}

It has been argued that taboo words are not inherently so. For example, $T\left(w^{3}\right)$ is not guaranteed to exist for all translation equivalents of $w^{3}$ in the world's languages and the cultures that use them. The discussion above supports the conclusion that being taboo is not an immediately predictable consequence of literal content. However, the connotative aspects of their meaning, once conventionalized, are a part of the meaning, and contextualization of the forms within communities of use do not change that. While impolite conversation is

\footnotetext{
${ }^{5}$ See [7, pp. 31-34] for discussion of these notions and the subsuming category of X-phemisms.

${ }^{6}$ In addition to the possibility that such a form does not exist is also the possibility that more than one is available.
}

not defined by the use of taboo forms, the use of taboo forms is evidently sufficient to render conversation impolite.

The taboos of sanctity (e.g., $T\left(w^{1}\right)$ ) appear to be beyond the distastefulness of excessive politeness [8]. In communities in which the terms no longer invoke sanctity, the use of such expressions with earnest attestment of belief can cause the same sort of embarrassment for witnesses as being party to conversations that include politeness at levels that reach obsequiosity.

Taboos have been studied from neurological perspectives. Evidence informing theories of cognitive architecture associated language processing suggest that taboo terms receive more shallow processing than neutral terms even though taboo expressions tend to be the easier to recall [22]. The cultural specificity of taboo bursts in Tourette's is noteworthy [2].

As hinted above, although manifestly differing with respect to literal semantics, relative to the connotations of contempt, $T\left(w^{3}\right)$ and $T\left(w^{4}\right)$ appear to be synonyms. Similarly, in terms of taboo semantics $T\left(w^{1}\right)$ appears to be a synonym of an arity1 version of $T\left(w^{2}\right) .{ }^{7}$ The single argument, a proto-patient, need not be articulated. Commonality of meaning between taboo of sanctity and revulsion is indicative of the circular spectrum of (im)politeness that has been noted [8] - excess politeness is not a prophylactic against disgust. As with other expressions, individuals may identify different use conditions that favor production of one over the other, but it is uncertain that their judgements of relative contempt indicated by the expressions will be stable over a sequence of days or be in agreement with offensiveness ranking judgements made by others. Thus, as with (im)politeness expressions, there appear to be equivalence classes of contempt associated with taboo forms.

Suppressed objects of verbs of excretion are available as antecedents to pronouns even though suppressed objects of other verbs are not accessible as discourse referents [23]. The contrasts for the potential antecedents (indicated with subscripts) of the pronoun it in the examples (11) and (12) show that the excrement (whether represented as $T\left(w^{5}\right)$, $\Omega\left(w^{5}\right)$ or $E\left(w^{5}\right)$ ), although unmentioned directly, is available as an antecedent, although the unmentioned object of a verb that does not evoke disgust is not accessible, as in (11). ${ }^{8}$

(11) After the gun fired, it the gun $/ \# \mathrm{it}_{\text {the bullet }}$ dropped to the ground.

(12) After the dog defecated, $\# \mathrm{it}_{\text {the }} \mathrm{dog} / \mathrm{it}_{\text {the excrement }}$ bore the missing ring.

Imagination is evidently more robust in constructing an unmentioned antecedents in situations normally associated with disgust than in the unmarked alternatives. This is consistent with the fact that the human disgust response involves rapid and vivid imagination in that the physical components of the response ensue as if contact with a disgust trigger had occurred, even when it has not: imagined contact is prerequisite

\footnotetext{
${ }^{7}$ The arity-2 version of $T\left(w^{2}\right)$ with an implied subject and expressed protopatient object may be uttered with a first, second or third-person object.

${ }^{8}$ The prefixed symbol (\#) is used to indicate semantic infelicity.
} 
to the disgust response subsequent to the initial triggering.

Constraints on the available syntactic categories along with remarkable flexibility in placement potential of taboo expressions have also been noted [24], [25].

\section{Summary}

Some of the curiosities of taboo language have been outlined. This paper explores the extent to which taboo language may be analyzed using a semantics for (im)politeness, with focus on the extremes of impoliteness.

\section{SEMANTICS OF (IM)POLITENESS}

The semantics outlined in this section draws on [8], [9].

\section{A. The semantic model}

Denotations of linguistic expressions of politeness and impoliteness may be taken to be sets of events constrained by predications of offence involving the triggering event participants and the speaker. ${ }^{9}$ This treatment allows both semantic and pragmatic analysis to make reference to a shared ontology: the underlying events.

Relevant properties of event types are declared in (13). Events are particulars which instantiate the type. ${ }^{10}$ An event token $e$ of the type $\hat{e}$ makes relevant relations true among arguments and has certain other properties, as specified. Events have temporality, tense, aspect, and mode. Any event particular $e$ fixes values for these features, according to the level of granularity with which it is viewed (see [29] on levels of event granularity). Event participants-proto-agents and protopatients (see [30]) — are characterized using syntactic person. Events have use and cost for each participant. A threevalued polarity system (with 1 representing positive value, 0 representing neutral value, and -1 representing negative value) is used in a simple calculus of use and cost to determine a net value. Table I provides a specification of the combination of use and cost values to yield net values.

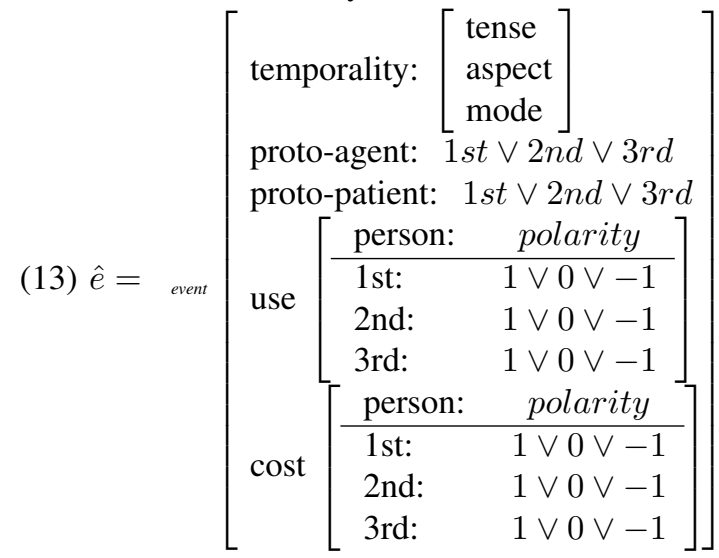

\footnotetext{
${ }^{9}$ Below (19) and (20) characterize the sets of events denoted by impoliteness and politeness expressions, respectively. The terms used are next to be explained. Understanding the denotations of these expressions as sets of events is not far removed from approaches to semantics that take denotations to be sets of supporting situations [26].

${ }^{10}$ Nested feature-value matrices provide structure for bundles of first-order logical descriptions. Feature logics and equations on paths through featurevalue structures are widely deployed [27], [28].
}

TABLE I

POSSIBLE $n e t$ OFFENCE/AFFINITY AS A FUNCTION OF $u s e$ AND cost

\begin{tabular}{|c|c|c|c|}
\hline use & 1 & 0 & -1 \\
\hline 1 & 1 & 1 & 0 \\
\hline 0 & 1 & 0 & -1 \\
\hline-1 & 0 & -1 & -1 \\
\hline
\end{tabular}

The relative offence $(\hat{o})$ an agent experiences in response to an event resolves the disjunctions in (14).

\begin{tabular}{|c|c|c|c|}
\hline \multirow{12}{*}{ (14) $\hat{o}(e)=$ attitude } & \multirow{3}{*}{ before- $e$ : } & person: & polarity \\
\hline & & 1st: & $1 \vee 0 \vee-1$ \\
\hline & & 2nd: & $1 \vee 0 \vee-1$ \\
\hline & \multirow{5}{*}{ during-e: } & & $1 \vee 0 \vee-1$ \\
\hline & & person: & polarity \\
\hline & & 1st: & $1 \vee 0 \vee-1$ \\
\hline & & 2nd: & $1 \vee 0 \vee-1$ \\
\hline & & & $1 \vee 0 \vee-1$ \\
\hline & \multirow{4}{*}{ after- $e$ : } & person: & polarity \\
\hline & & 1st: & $1 \vee 0 \vee-1$ \\
\hline & & 2nd: & $1 \vee 0 \vee-1$ \\
\hline & & 3rd: & $1 \vee 0 \vee-1$ \\
\hline
\end{tabular}

In a null context, speakers are assumed to maintain a default evaluation of interlocutors as in (15): the speaker has a default positive self-evaluation, and this is the same evaluation of all others. ${ }^{11}$ However, alternative temperaments may also be modelled.

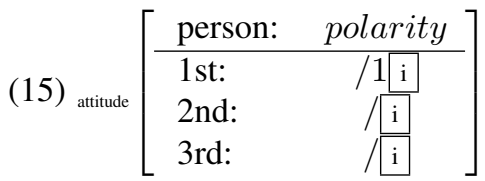

The contagion noted of disgust triggers is modelled with the sharing of the minimum value of the offence level as in (16). ${ }^{12}$ This is a worst-case formulation of contagion in which all share the contamination of any. Thus, the principle, even expressed as a conditional, is best understood as dependent on additional parameters left unspecified here.

(16) Contamination spreads

$$
\begin{aligned}
& (\operatorname{MIN}\{\hat{\mathrm{j}} \mid \exists \mathrm{i}, \hat{o}(e) \text { :after- } e \text { :person: } \mathrm{i} \text { :polarity: }] \mathrm{j}\}= \\
& -1) \Longrightarrow \forall \mathrm{k}, \hat{o}(e) \text { :after-e:person: } \mathrm{k}: \text { polarity } \doteq-1
\end{aligned}
$$

This framework can be used to model the interpretation of (im)polite utterances and to make predictions about linguistic and non-linguistic politeness behaviors that may emerge as a speaker evaluates an event and its participants [8], [9].

\section{B. Interpretation}

Expression of (im)polite language enables inference of further specification of $\hat{o}$ and $\hat{e}$. Expressions of impoliteness support the inference that the speaker's response to an event

\footnotetext{
${ }^{11} \mathrm{~A}$ framework for default feature logic is available [31]; the value to the right of the slash is defeasible. Co-indexing encodes value sharing.

${ }^{12}$ The "=" of the antecedent tests equality while the ".”" in the consequent is an assignment.
} 
$e^{\boldsymbol{a}}$ is consistent with the conjunction of (17.a) and (17.b). A neutral comment supports the inference of (18.a) and (18.b).

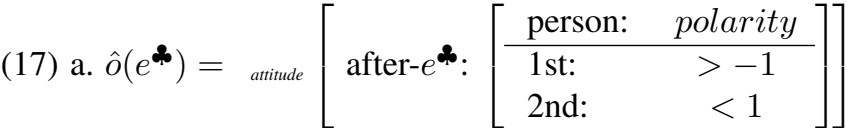

$$
\begin{aligned}
& \text { b. } \hat{o}\left(e^{\boldsymbol{m}}\right) \text { :after- } e^{\boldsymbol{\mu}} \text { :person:1st:polarity }>\hat{o}\left(e^{\boldsymbol{w}}\right) \text { :after- } \\
& e^{\mathbf{w}}: \text { person:2nd:polarity }
\end{aligned}
$$$$
\text { (18) a. } \hat{o}\left(e^{\dagger}\right)={ }_{\text {attitude }}\left[\text { after- } e^{\dagger}:\left[\begin{array}{ll}
\text { person: } & \text { polarity } \\
\hline 1 \text { st: } & 1 \vee 0 \vee-1 \\
2 \mathrm{nd}: & 1 \vee 0 \vee-1
\end{array}\right]\right]
$$$$
\text { b. } \hat{o}\left(e^{\dagger}\right) \text { :after- } e^{\dagger} \text { :person:1st:polarity }=\hat{o}\left(e^{\dagger}\right) \text { :after- }
$$$$
e^{\dagger}: \text { person:2nd:polarity }
$$

Impolite epithets may be taken to denote sets of events in which the speaker's self-estimation exceeds the speaker's estimation of others (19). Epithets of politeness denote sets of events constrained by the reverse relation (20).

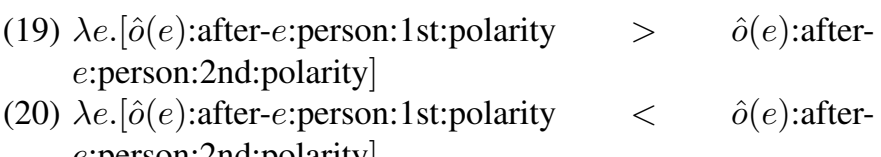
$e:$ person:2nd:polarity]

These denotations do not exhaust the meanings of corresponding expressions. However, within this theory, addressing someone as "fool" supports the same inference as addressing the person as "spittle", in terms of the speaker's estimation of the addressee versus the speaker's self-estimation. ${ }^{13}$ An issue at stake in this paper is discriminability of the taboo meaning contributions of $T\left(w^{3}\right)$ and $T\left(w^{4}\right)$.

\section{TABOO LANGUAGE SEMANTICS}

Consider $\llbracket T\left(w^{1}\right) \rrbracket$. A candidate interpretation is as specified in (21), following the reasoning that for the speaker to use a sacred name familiarly is to imply superiority or equality for the speaker, which would presumably be a contradiction in communities in which such expressions truly are sacred. Alternatively, the inferences that may be drawn follow from (22). Using this in conjunction with (16), an overhearer may infer that the speaker holds all present in contempt.

(21) $\lambda e \cdot[\hat{o}(e):$ after- $e$ :person:1st:polarity $\geq 1]$

(22) $\lambda e \cdot[\exists \theta \cdot(\hat{o}(e)$ :after- $e$ :person: $\theta$ :polarity $=-1)]$

As described in $§ I I-B,(22)$ also serves as the meaning contribution of the single argument version of $T\left(w^{2}\right)$. The alternative arity-2 form of $T\left(w^{2}\right)$ typically used with imperative syntax is provided as (23); it is a function from person values to sets of events that are constrained as before.

(23) $\lambda \theta \cdot \lambda e \cdot[\hat{o}(e):$ after- $e$ :person: $\theta:$ polarity $=-1]$

In fact, (23) also supports the inferences relevant to $T\left(w^{3}\right)$ and $T\left(w^{4}\right)$. A difference between arity-2 $T\left(w^{2}\right)$ on one hand and $T\left(w^{3}\right)$ and $T\left(w^{4}\right)$ on the other hand is in the syntaxsemantics interface. The former is syntactically a two-place relation as well as semantically, even though through the use in structures like imperatives, the proto-agent first argument is not realized. The latter have an argument role only for the

\footnotetext{
${ }^{13}$ Acidic delivery [32] or other forms of linguistic packaging may yield the same semantics.
}

proto-patient (which is not realized, either). Thus, the lexical semantics for these would introduce predications of the form (24) for arity-1 $T\left(w^{2}\right)$, (25) for arity-2 $T\left(w^{2}\right)$ and (26) for $T\left(w^{3}\right) \cdot{ }^{14}$

(24) $T\left(w^{2}\right)$ (proto-patient)

(25) $T\left(w^{2}\right)$ (proto-agent, proto-patient)

(26) $T\left(w^{3}\right)$ (proto-patient)

However, the inferences regarding (im)politeness for all of arity-1 and arity-2 $T\left(w^{2}\right)$ as well as $T\left(w^{3}\right)$ and $T\left(w^{4}\right)$ are those which are triggered by (23). ${ }^{15}$

Again, for each of these relations, the background principle (16) is in force, so from an utterance of any of these expressions, it is reasonable for a co-present over-hearer to conclude that all present, including the speaker, are thought of with contempt by the speaker.

It is also reasonable to reflect on the fact that in some communities of practice the expressions considered here are used without the speakers actually feeling disgust with all present. More than denying the implications from (16), in those circumstances one might also wish to deny the predications directly conveyed by the expressions. However, it is possible to adapt a reply made by Davidson with respect to metaphorical predications [34]: disgust really is part of the meaning of these expressions, just as literal meanings are part of the baggage of metaphorical utterances. ${ }^{16}$ In the relevant communities of practice, however, contempt, as denoted, is not understood literally. Recall (18) as an indication of inferences supported by neutral expressions. This is consistent with the polarity resolution of (18.a) as -1 , since the consequence is that this value is shared between addresser and addressee. The relevant observation is that in such a community of practice where offensive forms are the norm, it is safe to conclude that while negative polarity is expressed, superiority of one interlocutor over another is not.

Above, (23) is taken as the denotation of both $T\left(w^{3}\right)$ and $T\left(w^{4}\right)$. This reveals that the semantic framework as currently articulated is not sufficiently expressive to capture graduations of taboo, such as would be necessary to allow both to be understood as taboo, but one more so than the other. While one approach to accommodating comparative taboo would be to allow for the full range of values in the interval $[-1,1]$ with some notion of taboo thresholds applying to this range, the evidence at hand is also compatible with a solution that renders polarity as a structured object that combines the former value

\footnotetext{
${ }^{14}$ To accommodate both the literal lexical semantics of expressions, and non-literal senses, a system of sense-indexed evaluation is available [33].

${ }^{15}$ The syntax-semantics interface provides some guidance on resolving the proto-patient with the abstracted person role, $\theta$, in (23). For example, where the lexical semantics is as in (25), the realized argument can be identified as in first, second or third, person. For (24) and (26), the unrealized proto-patient may be identified as third-person if the predication is realized as a definite noun phrase (e.g., "the $T\left(w^{2}\right)$ ") or as second-person, according to whether direct address is involved explicitly (e.g., "you $T\left(w^{2}\right)$ ") or implicitly. Similar considerations apply to $T\left(w^{3}\right)$ and $T\left(w^{4}\right)$.

${ }^{16}$ It must be acknowledged that Davidson probably would not have agreed with this adaptation, since his position was stronger: "metaphors mean what the words, in their most literal interpretation, mean, and nothing more" [34, p. 245, emphasis added].
} 
with a binary feature that indicates whether any other objects have a comparatively "more substantial value" for the given polarity level (or whether the value is a "superlative" such that no other value has greater magnitude for the valence).

$(27)_{\text {polarity }}\left[\begin{array}{ll}\text { valence: } & -1 \vee 0 \vee 1 \\ \text { superlative: } & 0 \vee 1\end{array}\right]$

Thus, given structured polarity values such as in (27), two possible instantiations are given in (28) and (29). A structured polarity value such as (28) indicates positive valence, with respect to which nothing more positive is available. Similarly, (29) indicates neutral valence, but with respect to which items that are potentially "more neutral" are acknowledged. ${ }^{17}$ Using such an encoding, the polarity for $T\left(w^{3}\right)$ could be as in (30), and $T\left(w^{4}\right)$, as in (31). That is, (30) indicates that the polarity valence is maximal, and therefore cannot be exceeded, while valences of greater magnitude than (31) can be contemplated (e.g. (30) would be such an exceeding value).

$(30)_{\text {polarity }}\left[\begin{array}{lc}\text { valence: } & -1 \\ \text { superlative: } & 1 \\ \text { valence: } & -1 \\ \text { superlative: } & 0\end{array}\right]$

Thus, the contradictory polarity assertion from (22) can be reconstructed using the structured polarity object (32)

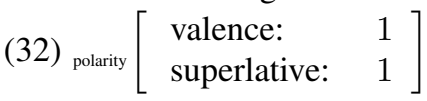

This, as a speaker self-estimation, would then be understood to clash within a value system that, by hypothesis, accords such a valuation only to a deity. While using structured polarity values as in (30) and (31) would separate $T\left(w^{3}\right)$ and $T\left(w^{4}\right)$ in relation to their semantics with respect to impoliteness, clearly, this does not allow for infinite polarity graduations. However, it is not clear that infinite distinctions are reliable empirical possibilities in this context.

An example discussed above (12) is interesting partly because of the demonstration of robust capacities to construct unmentioned antecedents for pronouns, and also in illustrating that pronouns may serve as euphemisms. The referent of the pronoun in the context of (12) is $w^{5} \cdot{ }^{18}$ However, the use of the pronoun as a euphemism also conveys politeness (33). ${ }^{19}$

(33) $\lambda e .[\exists \theta .(\hat{o}(e)$ :after-e:person: $\theta$ :polarity $>0)]$

In contrast, orthophemisms are neutral politic expressions [36].

\section{NON-LINGUISTIC TABOO}

Non-linguistic communication may also be approached from the perspective of model-theoretic semantics. Physical

\footnotetext{
${ }^{17}$ Compare this notion with that of equality on Animal Farm - "All animals are equal, but some animals are more equal than others". This would not appear to be the only aspect of human categorization that evoke Orwellian equivalence classes [35].

${ }^{18}$ Again, the speaker may entertain a linguistic representation of $w^{5}$ with any of $T\left(w^{5}\right), \Omega\left(w^{5}\right)$ or $E\left(w^{5}\right)$.

${ }^{19}$ In this example, presumably $\theta$ resolves as the addressee.
}

assault is an example of communicative non-linguistic taboo. Physical assaults denote sets of events which give the author of a punch an estimation of the recipient sufficiently negative to erase inhibitions that might otherwise thwart assault (34).

(34) $\lambda e .[\hat{o}(e)$ :after-e:person:2nd:polarity $=-1]$

Again, relative to taboo semantics, if not accounting for differential physical injury, a physical assault is synonymous with obscene gesture or verbal insult. German law codifies their similarity with comparable scales of penalty for obscene gesture, verbal insult and physical assault: obscene gesture and insult trigger penalty of up to a year in prison or a fine and physical assault elicits up to two years in prison or a fine [37], [38]. Further, this semantics admits attribution of truth or falsity in non-linguistic taboo. "Horse-play" can be characterized as having most of the same properties as physical assault ${ }^{20}$ yet it fails to denote (34). A bystander might perceive the meaning of horse-play as (34), but it can be meaningfully said that this perception is wrong-horse-play is not true assault and does not convey its author's contempt, one may argue.

\section{FINAL REMARKS}

This paper has addressed part of the contributions to meaning of taboo language, using the semantics of impoliteness. While the semantic framework is useful for anchoring discussion of non-linguistic impoliteness and politeness behaviors, the extent to which it provides analysis to non-linguistic taboo, such as in communication with images or other potential behaviors, is relatively less explored, and interactions across modalities less again. Empirical investigation in this direction exists. For example, [39] shows that image based content that would likely create concern for anyone inclined to filter offensive content hosted within microblog accounts is more likely to be associated with microblog account names derived from common words that that expresses negative sentiment than words that express positive sentiment. However, positive sentiment words were also used as account names for blogs hosting offensive content. Relative dominance of modalities in the expression of emotions has been studied (for example, see [40]), but more empirical work is necessary to understand the how potentially conflicting indications are accommodated.

Conformity and conflict in information arising across modalities may be realized in the present framework in further instantiation of $\hat{e}$ and $\hat{o}$. This article has not analyzed the cognition-internal flow of information from functional modules (cf. [41]) nor the processes by which these information flows integrate into an overall perception and response to taboo. A work like that of [42], which addresses cognitioninternal levels of representation and cross-module communication inherent within cognitive infocommunication may be refined to specify the particulars of modality-specific contributions to the perception of offence in the context of any triggering event.

The semantics developed here analyzes taboo language as at the extreme of impoliteness. Attention is therefore given to

\footnotetext{
${ }^{20}$ Perhaps bared teeth are less likely during horse-play than during assault.
} 
the aspects of meaning of taboo expressions that support valid inference about the speaker's evaluation vis-à-vis offensiveness of interlocutors. Consequently, most other aspects of lexical semantics are not emphasized. The semantics is based on a conventional ontology of events and individuals who participate in them and interact with each other. A structured notion of polarity has been introduced in order to accommodate equivalence classes of relative offence with maximal elements.

\section{ACKNOWLEDGMENT}

This research is supported by the Science Foundation Ireland funded Centre for Global Intelligent Content (12/CE/I2267; www.cngl.ie). Interaction with members of COST Actions 2102 ("Cross Modal Analysis of Verbal and Nonverbal Communication") and IS1004 ("WEBDATANET") have enhanced this work.

\section{REFERENCES}

[1] S. Freud, Totem and Taboo. Prometheus Books: Amherst, New York, 1918, translated by A. A. Brill, reprinted 2000.

[2] T. Jay, "The utility and ubiquity of taboo words," Perspectives on Psychological Science, vol. 4, no. 2, pp. 153-161, 2009.

[3] T. McEnery, Ed., Swearing in English: Bad Language, Purity and Power from 1586 to the Present. Routledge: London, 2006.

[4] E. Crespo Fernández, "Conceptual metaphors in taboo-induced lexical variation," Revista Alicanta de Estudios Ingleses, vol. 24, pp. 53-71, 2011.

[5] C. Goddard, "The search for the shared semantic core of all languages," in Meaning and Universal Grammar: Theory and Empirical Findings., C. Goddard and A. Wierzbicka, Eds. John Benjamins, 2002, vol. I, pp. 5-40.

[6] C. Goddard and A. Wierzbicka, "Semantic primes and universal grammar," in Meaning and Universal Grammar: Theory and Empirical Findings, C. Goddard and A. Wierzbicka, Eds. John Benjamins, 2002, vol. I, pp. 41-85.

[7] K. Allan and K. Burridge, Forbidden Words: Taboo and the Censoring of Language. Cambridge University Press, 2006.

[8] C. Vogel, "Some puzzles of politeness and impoliteness within a formal semantics of offensive language," in Conflict and negotiation: Social research and machine intelligence, F. D'Errico, A. Vinciarelli, I. Poggi, and L. Vincze, Eds., 2014, to appear.

[9] — - "Denoting offence," Cognitive Computation, 2014, to appear: http: //link.springer.com/article/10.1007/s12559-014-9289-5.

[10] A. Kolnai, "Disgust," in On Disgust, B. Smith and C. Korsmeyer, Eds. Open Court Press: Chicago, 2004 (1929), pp. 29-91, translated by Elisabeth Gombrich, Elizabeth Kolnai and Barry Smith.

[11] _ _The standard modes of aversion: Fear, disgust and hatred," in On Disgust, B. Smith and C. Korsmeyer, Eds. Open Court Press: Chicago, 2004 (1929), pp. 93-108, translated by Elisabeth Gombrich, Elizabeth Kolnai and Barry Smith.

[12] D. Kelly, Yuck! The Nature and Moral Significance of Disgust. MIT, 2011.

[13] A. Wierzbicka, "Human emotions: Universal or culture-specific?" American Anthropologist, vol. 88, no. 3, pp. 584-594, 1986.

[14] C. Vogel, "Intended and unintended offence," in Recent Advances of Neural Network Models and Applications, ser. Smart Innovation, Systems and Technologies Volume 26, S. Bassis, A. Esposito, and F. C. Morabito, Eds. Springer International Publishing, 2014, pp. 395-404.

[15] J. Culpeper, Impoliteness: Using Language to Cause Offense. Cambridge University Press, 2011.

[16] E. Goffman, The Presentation of Self in Everyday Life. New York: Doubleday, 1956.

[17] — , "On face-work," in Interaction Ritual: Essays in Face-to-Face Behavior. New Brunswick, NJ: Transaction Publishers, 1967, pp. 545, reprinted 2008.

[18] P. Brown and S. Levinson, Politeness: Some Universals in Language Usage. Cambridge University Press, 1987.
[19] M. Locher and R. Watts, "Relational work and impoliteness: Negotiating norms of linguistic behaviour," in Impoliteness in Language: Studies on its Interplay with Power in Theory and Practice, D. Bousfield and M. Locher, Eds. Berlin: Mouton de Gruyter, 2008, pp. 77-99.

[20] D. Bousfield and M. Locher, Eds., Impoliteness in Language: Studies on its Interplay with Power in Theory and Practice. Berlin: Mouton de Gruyter, 2008

[21] J. Culpeper, "Reflections on impoliteness, relational work and power," in Impoliteness in Language: Studies on its Interplay with Power in Theory and Practice, D. Bousfield and M. Locher, Eds. Berlin: Mouton de Gruyter, 2008, pp. 17-44.

[22] T. Jay, C. Caldwell-Harris, and K. King, "Recalling taboo and nontaboo words," American Journal of Psychology, vol. 121, no. 1, pp. 88-103, 2008.

[23] P. R. N. Tic Douloureux, "A note on one's privates," in Studies out in Left Field: Defamatory Essays Presented to James D. McCawley, A. Zwicky, P. H. Salus, R. I. Binnick, and A. L. Vanek, Eds. John Benjamins: Philadephia, 1992, pp. 45-51, originally published in 1971.

[24] Q. P. Dong, "English sentences without overt grammatical subject," in Studies out in Left Field: Defamatory Essays Presented to James D. McCawley, A. Zwicky, P. H. Salus, R. I. Binnick, and A. L. Vanek, Eds. John Benjamins: Philadephia, 1992, pp. 3-10, originally published in 1971 .

[25] U. P. Shad, "Some unnatural habits", in Studies out in Left Field: Defamatory Essays Presented to James D. McCawley, A. Zwicky, P. H. Salus, R. I. Binnick, and A. L. Vanek, Eds. John Benjamins: Philadephia, 1992, pp. 33-36, originally published in 1971.

[26] A. Cohen, "No alternative to alternatives," Journal of Semantics, vol. 26, no. 1, pp. 1-48, 2009. [Online]. Available: http://jos.oxfordjournals.org/ content/26/1/1.abstract

[27] R. Kasper and W. Rounds, "A logical semantics for feature structures," in Proceedings of the 24th Annual Meeting of the Association for Computational Linguistics. Columbia University, New York, NY, 1986, pp. 257-266.

[28] B. Carpenter, The Logic of Typed Feature Structures. Cambridge Tracts in Theoretical Computer Science 32, Cambridge: Cambridge University Press, 1992.

[29] T. Fernando, "Segmenting temporal intervals for tense and aspect," in Proceedings of the 13th Meeting on the Mathematics of Language. Association for Computational Linguistics, 2013, pp. 30-40.

[30] D. Dowty, "Thematic proto-roles and argument selection," Language, vol. 67, no. 3, pp. 547-619, 1991.

[31] A. Lascarides, T. Briscoe, N. Asher, and A. Copestake, "Order independent and persistent typed default unification," Linguistics and Philosophy, vol. 19, no. 1, pp. 1-89, 1996.

[32] F. D'Errico and I. Poggi, "Acidity. The hidden face of conflictual and stressful situations," Cognitive Computation, 2014, to appear: http://link. springer.com/article/10.1007/s12559-014-9280-1.

[33] C. Vogel, "Dynamic semantics for metaphor," Metaphor and Symbol, vol. 16 , no. 1 \& 2, pp. 59-74, 2001

[34] D. Davidson, "What metaphors mean," in Inquiries into Truth and Interpretation, D. Davidson, Ed. Oxford: Oxford University Press, 1984, pp. 245-64.

[35] R. Bortoloti and J. C. de Rose, "An "Orwellian" account of stimulus equivalence. Are some stimuli "more equivalent" than others?" European Journal of Behavior Analysis, vol. 12, pp. 121-134, 2011.

[36] R. J. Watts, Politeness. Cambridge University Press, 2003.

[37] I. P. Robbins, "Digitus Impudicus: The middle finger and the law," $U$. C. Davis Law Review, pp. 1403-1486, 2008.

[38] J. Q. Whitman, "Enforcing civility and respect: Three societies," The Yale Law Journal, vol. 109, no. 6, pp. 1279-1398, 2000.

[39] C. Vogel, "Multimodal conformity of expression between blog names and content," in 4th IEEE International Conference on Cognitive Infocommunications, P. Baranyi, A. Esposito, M. Niitsuma, and B. Sølvang, Eds., 2013, pp. 23-28.

[40] M. T. Riviello, A. Esposito, and K. Vicsi, "A cross-cultural study on the perception of emotions: How Hungarian subjects evaluate American and Italian emotional expressions," in Cognitive Behavioural Systems, A. Esposito, A. M. Esposito, A. Vinciarelli, R. Hoffmann, and V. C. Müller, Eds. Springer, LNCS 7403, 2012, pp. 424-448.

[41] J. A. Fodor, The Modularity of Mind. Cambridge: MIT Press, 1983.

[42] A. Csapo and P. Baranyi, "Coginfocom channels and related definitions revisited," in IEEE 10th Jubilee International Symposium on Intelligent Systems and Informatics (SISY), 2012, pp. 73-78. 